\title{
Copperplating One's Navel
}

\section{by Michael Lipton*}

The very rich, disturbed by noise and fumes from the badly-maintained cars of poor people in their own country, have been campaigning with increasing success to preserve an environment that has little to do with rendering tolerable, for the workers who live there, such real black spots as Gary, Indiana, or the Gorbals. This selective environmental concern has acquired a pseudo-liberal underpinning in the form of almost hysterical threats (usually totally lacking in careful scholarly support) that we shall run out of essential minerals, or pollute our air and water beyond redemption, unless (now that the rich have enough) we stop trying to increase available income. Nobody has ever shown that such ecological disasters as the destruction of Lake Erie could have been prevented by slower growth; or that they have become more frequent during (let alone because of) affluence. Nobody with the slightest knowledge of the conditions under which working people lived in Britain between 1815 and 1850 could seriously contend that the environment enjoyed by most of the people, most of the time, is worse now than it was then. Indeed almost all the subsequent improvements are the result of increasingly carefully directed growth.

The threats of exhaustion of mineral supplies, melting of the polar ice cap, and similar pieces of science fiction need be taken no more seriously now than were the constant threats in the mid nineteenth century that further growth (apart from favouring those less wel1-off than the Cassandras) would exhaust the reserves of coal, or bring down the wrath of God in some other way. The really serious threat is that posed

* Michael Lipton is an IDS Fellow. 
by ultra-envi ronmentalists to the improved wellbeing of people in the Third World. Pollution and poverty are surely nowhere worse than in Calcutta; by il1judged environmental extremism in the West, we risk making it more difficult for people in such places to climb out of the pollution by alleviating the poverty. There are four ways in which this is a serious risk.

The first concerns the spread, among intellectuals at conferences financed out of the fruits of growth and develonment, of trendy notions of vicarious ascetisicm. Economists state, with a frequency sometimes mistaken for evidence, that the hectic pursuit of growth in rich countries has produced all sorts of problems of pollution, ranging from impure air and water to the psychological pollution implied by higher crime and insanity rates. The elites of poor countries, who are personally often rich and have therefore built for themselves sheltered environments susceptible to problems closer to those of London than to those of an Indian village, are only too prone to follow the lead given to them by their western colleagues. It can be argued in a very rich country that further increases of income should be foregone in the interest of silence, beauty or privacy. Such an argument is absurd in a less-developed country, where mass poverty obviously constitutes the main threat to these humanist ideals. ${ }^{1}$ Even in the West, we have the power to make growth and development good for our environment, and only very doubtfully the capacity to improve the environment if we stagnate. In less developed countries,

1 "Whilst it is not yet proven that the organomercurial seed dressings increase the mercury level in plants... and evidence to this effect would probably lead to a recommendation by the WHO expert committee on pesticide residues that their use by discontinued or restricted". (Provisional Indicative World Plan (FAO, Rome, 1969), Vol. I, page 217). In other words, a lot of mercury is bad for us, so we shall prevent you from using mercurial pesticides to stop yourselves starving -- even if we cannot show they suffice ho harm you -- and pat ourselves on the back for our decency. See also the almost desperate warnings given to the FAO Congress in Rome, November 1971, by Professor Borlaug (justly awarded the Nobel Prize for his work on impoved wheats), that the spread of ecomaniac opposition to DDT could in the near future become a direct cause of starvation in the Third World. 
economic stagnation ensures pollution; the poor cannot afford to be pure.

The second way in which the new and illogical argument that because the environment is getting worse (which is not proved) we should curtail growth to make it better (which is not proved) threatens poor countries is less direct. A deliberate curtailment of growth would curtail imports from many poorer countries much more than in proportion. This is because many of the things sold to us by poor countries -- tin, rubber, copper -- are goods used for the process of growth itself. If the West stops growing in the irrational hope of thereby improving its environment, the South will suffer not merely a reduction in growth but an actual and sharp decline in those parts of its standard of living which are made possible by export receipts.

A retardation of growth in the West will almost certainly also decrease aid; it is noteworthy that during the $1960^{\prime} \mathrm{s}$ it was the faster growing countries which managed to increase the total aid transferred to the Third World. (Anti-colonialists need not hope that private foreign investment would be curtailed if the rich world stopped growing; investors would merely find the poor world more attractive in comparison).

The third drawback of extreme environmentalism for the development process lies in the resentment it is likely to cause among those people who are not taken in by it in poor countries. Extra pollution is plainly caused by the unplanned and undirected consumption patterns of extra, high-consuming people in rich countries. If these countries force the Third World to bear the effective costs of their attempts (however unsuccessful) to become environmentally clean, resentment will surely be severe.

The final and perhaps the most serious threat that extreme environmentalism poses to poor countries lies in the fact that both people and energy for good causes are in short supply. If they are directed towards cleaning up the environment -- whether or not effectively -they will not be available to further the cause of decent trading arrangements, sufficient aid on proper terms, the transfer of appropriate technologies, a reduction in the exploitation associated with many movements of private capital, and other matters of vital concern to poor countries. We are already seeing, 
in the universities of the United States and Britain, a creeping intellectual pollution. The young people who ten years ago spent their time and energy working for the alleviation of gross poverty, at home as well as in poor countries, are more and more concerning themselves with traffic congestion, smoke pollution and clean bathing water in their own back yards. Mr. Nixor, even for some members of the radical left, can regain popularity lost in Vietnam (or in aid and trade policies vis-a-vis poor countries) by his zeal in supporting Earth Days, ministries responsible for the environment, safety legislation to keep out imported cars, and other gimmicks. The Third World -- now (as always) in much greater danger from being ignored than from being exploited -- suffers increasing neglect, while those who should be organising and informing our concern for it are instead copperplating their navels. 